\title{
Phenotypic Variation of Autosomal-Dominant Corticobasal Degeneration
}

\author{
Hans H. Jung ${ }^{a} \quad$ Juliane Bremer ${ }^{a} \quad J^{\prime}$ hannes Streffer ${ }^{b} \quad K^{2}$ anwar Virdee ${ }^{e}$ \\ Maria Grazia Spillantini ${ }^{\mathrm{e}} \quad$ R. Anthony Crowther ${ }^{f}$ Peter Brugger $^{\mathrm{a}}$ \\ Christine Van Broeckhoven ${ }^{g, h}$ Adriano Aguzzic Markus Tolnay ${ }^{d}$ \\ ${ }^{a}$ Department of Neurology, University Hospital Zurich, ${ }^{b}$ Division of Psychiatry Research, University of Zurich \\ and ${ }^{\mathrm{C}}$ Department of Pathology, Institute of Neuropathology, University Hospital Zurich, Zurich, and ${ }^{\mathrm{d}}$ Institute of \\ Pathology, Department of Neuropathology, University Hospital Basel, Basel, Switzerland; ${ }^{\mathrm{e} D e p a r t m e n t}$ of Clinical \\ Neurosciences, Brain Repair Centre, University of Cambridge, and ${ }^{f}$ Medical Research Council, Laboratory of \\ Molecular Biology, Cambridge, UK; ${ }^{9}$ Neurodegenerative Brain Diseases Group, Department of Molecular Genetics, \\ VIB, and h Laboratory of Neurogenetics, Institute Born-Bunge, University of Antwerp, Antwerp, Belgium
}

\section{Key Words}

Corticobasal degeneration - Progressive supranuclear palsy • Primary progressive aphasia $\cdot$ Tauopathy

\begin{abstract}
Neurodegenerative tauopathies may be inherited as autosomal-dominant disorders with variable clinicopathological phenotypes, and causative mutations in the microtubuleassociated protein tau (MAPT) gene are not regularly seen. Herein, we describe a patient with clinically typical and autopsy-proven corticobasal degeneration (CBD). Her mother was diagnosed to have Parkinson's disease, but autopsy showed CBD pathology as in the index patient. The sister of the index patient had the clinical symptoms of primary progressive aphasia (PPA), but no pathology was available to date. Molecular analysis did not reveal any mutation in the $M A P T$ or progranulin (GRN) genes. Our findings illustrate that $C B D$, progressive supranuclear palsy and PPA may be overlapping diseases with a common pathological basis rather than distinct entities. Clinical presentation and course might be determined by additional, yet unknown, genetic modifying factors.

Copyright $\odot 2012$ S. Karger AG, Basel
\end{abstract}

\section{Introduction}

Neurodegenerative tauopathies include frontotemporal lobar degeneration (FTLD) and tauopathies with prominent extrapyramidal features like progressive supranuclear palsy (PSP), corticobasal degeneration (CBD), and hereditary frontotemporal dementia with Parkinsonism linked to chromosome 17 associated with tau gene mutations (FTDP-17T) [1-3]. Although distinct clinical and neuropathological criteria have been elaborated which allow differentiation between these disorders, clinical and pathological overlap is frequently seen [4-6]. In addition to FTLD with tau-positive inclusions (FTLDtau), FTLD may be associated with TDP-43 (TAR DNAbinding protein 43)-positive inclusions (FTLD-TDP), FUS (fused in sarcoma)-positive inclusions (FTLD-FUS), or may be linked to chromosome 3 (FTD-3; FTLD-UPS) [7].

Alternative mRNA splicing of MAPT leads to six tau isoforms in the adult human brain, consisting of three tau isoforms with four tandem repeats (4R), and three isoforms with three repeats (3R). In normal adult human brains, similar levels of $3 \mathrm{R}$ and $4 \mathrm{R}$ tau isoforms are present [8]. The molecular hallmark of neurodegenerative

\section{KARGER}

Fax +41613061234 E-Mail karger@karger.ch www.karger.com (c) 2012 S. Karger AG, Basel 0014-3022/12/0673-0142\$38.00/0

Accessible online at: www.karger.com/ene
Prof. Dr. Hans H. Jung

Department of Neurology, University Hospital Zürich

Frauenklinikstrasse 26

CH-8091 Zürich (Switzerland)

Tel. +41 44255 5545, E-Mail hans.jung@usz.ch 


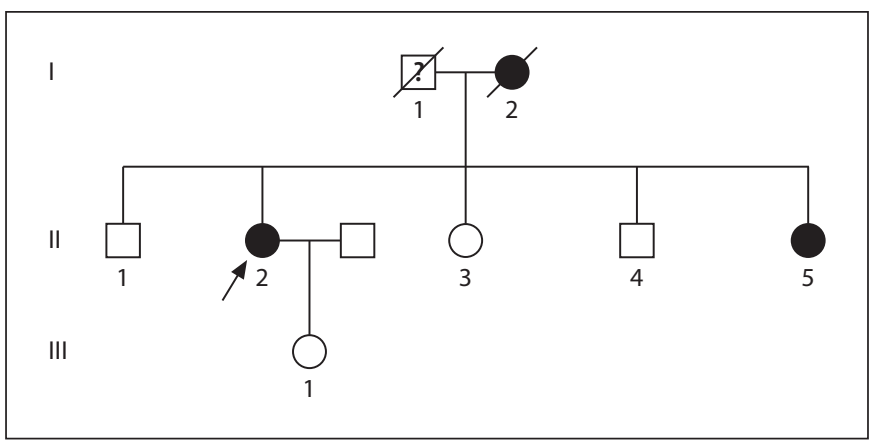

Fig. 1. Pedigree. The arrow indicates the index patient. Circles represent females, and squares represent males. Filled symbols represent affected family members. Open symbols represent clinically unaffected individuals.

tauopathies is the aggregation of particular tau isoforms. In extrapyramidal tauopathies, like PSP, CBD, and a subset of FTDP-17T families, aggregation of predominantly $4 \mathrm{R}$ tau isoforms was demonstrated, while in others tauopathies filamentous tau aggregates may consist predominantly of 3R (Pick's disease), 4R (argyrophilic grain disease) or a mixture of both, $3 \mathrm{R}$ and $4 \mathrm{R}$ tau isoforms (subset of FTDP-17T cases) $[1,9]$.

A hereditary $4 \mathrm{R}$ extrapyramidal tauopathy caused by MAPT mutations was initially described in families with the FTDP-17 phenotype [10]. Later it was recognized that different members of the same kindred with hereditary $4 \mathrm{R}$ extrapyramidal tauopathy may exhibit diverse symptoms encompassing the features of FTDP-17, PSP or CBD $[6,11]$. In addition, sporadic PSP and CBD share a common MAPT haplotype that increases risk for disease [12, 13]. Therefore, the clinical and pathological phenotypes of hereditary $4 \mathrm{R}$ tauopathies may represent different points within one disease spectrum. Since MAPT mutations were not regularly found in patients with hereditary tauopathies, additional genetic or epigenetic factors might contribute to the phenotypic diversity.

Here, we describe a family with an autosomal-dominant 4R tauopathy without pathogenic MAPT or GRN mutation with phenotypic variation, manifesting as CBD, parkinsonism or, presumably, primary progressive aphasia (PPA).

\section{Patients and Methods}

The family originates from the German-speaking part of Switzerland (fig. 1). All consenting family members underwent neurological examination, neuropsychological testing and molecular genetic analysis. Extended laboratory analysis, magnetic resonance imaging (MRI), and $\left[{ }^{18} \mathrm{~F}\right]$-FDG (2-fluoro-2-deoxy-glucose) positron emission tomography (PET) were performed in the index patient and her sister. In addition, available medical records of the deceased family members were studied. Brain autopsy was performed in the index patient (II-2) and paraffin-embedded tissue was available from a former autopsy of her mother (I-2).

Molecular Genetic Analysis

DNA was extracted using standard protocols (QIAamp, QIAGEN, Hilden, Germany). Primer sequences were designed according to GenBank entries and are available on request. PCR amplification was done by a universal 'touch down' protocol, and amplicons were sequenced by fluorescent dye dideoxy terminators on an ABI PRISM ${ }^{\circledR}$ (Applied Biosystems, Forster City, Calif., USA). Exons 1, 7, 9-13 and 16 of the MAPT gene, including the flanking intronic regions, were analyzed, thus covering all genomic regions with known mutations. GRN sequence analysis was performed as previously described [14].

\section{Neuropathology}

Brain autopsy was performed in the index patient. From her mother, paraffin-embedded brain tissue was available for re-evaluation. No brain tissue was available from the index patient's sister.

From the index patient, sections $(3 \mu \mathrm{m})$ were subjected to conventional stains, including the Gallyas silver technique. Immunohistochemistry was performed with anti-tau antibodies AT8 (phospho-epitopes Ser202 and Thr205; Innogenetics, Ghent, Belgium), RD3 (3R tau isoform; Upstate, Lake Placid, N.Y., USA), RD4 (4R tau isoform; Upstate), alpha-synuclein (human alphasynuclein; Zymed, San Francisco, Calif., USA), ßA4 (human betaamyloid; DAKO, Glostrup, Denmark), 3F4 (PrP; Signet, Denham, Mass., USA), neurofilament (SMI31; phosphorylated epitopes on the largest neurofilament subunit; Sternberger Monoclonals, Lutherville, Mass., USA), $\alpha$ B-crystallin (Novocastra, Newcastle-upon-Tyne, UK) and glial fibrillary acidic protein (GFAP; Lab Vision Corporation, Newmarket, Suffolk, UK). Sarkosyl-insoluble tau proteins were extracted from the index patient's frontal and temporal cortices, hippocampus, striatum and spinal cord. Western blot analysis, electron microscopy and immuno-electron microscopy were performed as previously described [15]. Micrographs were recorded at a magnification of $\times 40,000$ (Philips EM208S microscope). Dephosphorylation assays were performed as previously described [15].

\section{Results}

\section{Case Report of the Index Patient}

At 54 years, the right-handed patient (II-2) had difficulties to recognize traffic signs or to relocate her car on a parking lot. During the following months, clumsiness of her left hand developed, and she became unable to work as a beautician. One year later, the first neurological examination at our department revealed psychomotor slowing, left homonymous hemianopsia, marked dysto- 
nia of the left arm without spasticity and slight distal weakness (MRC grade M4-5). Muscle tone, strength, and coordination of the right arm and both legs were normal. No involuntary movements were observed. Tendon reflexes were brisk on the left and normal on the right side, plantar responses were flexor. Sensory examination revealed impaired joint position sense on the left side. Cognitive testing demonstrated a right parietal lobe syndrome with neglect, agnosia for affective facial expressions, visuoconstructive deficits, ideomotor apraxia and figural, but not verbal, memory deficits. Language functions were preserved. CSF examination as well as extended laboratory investigations were normal.

Based on the clinical findings, CBD was assumed. Two years after onset, neurological examination revealed marked dystonia of the left arm with almost complete loss of functionality due to dystonia, apraxia, and neglect. The other neurological findings were unchanged and no alien limb phenomenon had developed. Repeated CSF analysis showed strong positivity for protein 14-3-3. Over the following three years, she progressively deteriorated. Dystonia generalized, albeit predominance of the left arm remained, she became wheelchair-dependent and finally bedridden. Five and a half years after onset she suddenly reported severe abdominal pain. Colon perforation was diagnosed and she died $36 \mathrm{~h}$ later due to septic peritonitis.

\section{Family Evaluation}

The father of the index patient died at the age of 90 years without history of psychiatric or neurological problems. After 61 years, the mother of the index patient developed progressive gait problems, frequent falls, bradykinesia, cognitive deterioration, and swallowing difficulties, and parkinsonism was diagnosed. At the age of 73 years she died due to cardio-respiratory failure. Retrospectively, the predominant gait problems are suggestive of a PSP-like phenotype.

The sister (II-3) of the index patient had progressive word-finding difficulties after 60 years. At 62 years, she demonstrated isolated deficits in language functions, including stagnant spontaneous speech, word-finding difficulties, semantic and phonematic paraphasias, and mild paragrammatism. Reading was slow and stagnant, and there were paralexias of long words. Repetition and writing of dictated long and complex sentences were erroneous. Language comprehension was intact. No deficits in other cognitive functions were identified, and she was diagnosed with PPA.
Table 1. Clinical and molecular characteristics

\begin{tabular}{|c|c|c|c|c|c|c|}
\hline $\begin{array}{l}\text { Pro- } \\
\text { band }\end{array}$ & Age & $\begin{array}{l}\text { Gen- } \\
\text { der }\end{array}$ & $\begin{array}{l}\text { PRNP } \\
\text { deletion } \\
\text { analysis }\end{array}$ & $\begin{array}{l}\text { PRNP } \\
\text { codon } \\
129\end{array}$ & $\begin{array}{l}\text { Neurological } \\
\text { phenotype }\end{array}$ & $\begin{array}{l}\text { Cognitive } \\
\text { abnormalities }\end{array}$ \\
\hline $\mathrm{I}-2$ & 73 & $\mathrm{f}$ & $\mathrm{del} / \mathrm{wt}$ & n.a. & $\begin{array}{l}\text { Parkinsonian } \\
\text { syndrome }\end{array}$ & n.p. \\
\hline II-1 & 59 & $\mathrm{~m}$ & $\mathrm{del} / \mathrm{wt}$ & $\mathrm{M} / \mathrm{M}$ & normal & $(+)$ \\
\hline II-2 & 57 & $\mathrm{f}$ & del/del & $\mathrm{M} / \mathrm{M}$ & $\mathrm{CBD}$ & +++ \\
\hline II-3 & 55 & $\mathrm{f}$ & $\mathrm{del} / \mathrm{wt}$ & $\mathrm{M} / \mathrm{M}$ & PPA & + \\
\hline II-4 & 53 & $\mathrm{~m}$ & $\mathrm{del} / \mathrm{wt}$ & $\mathrm{M} / \mathrm{V}$ & normal & none \\
\hline II-5 & 51 & $\mathrm{f}$ & $\mathrm{del} / \mathrm{del}$ & $\mathrm{M} / \mathrm{M}$ & normal & $(+)$ \\
\hline III-1 & 32 & $\mathrm{f}$ & $\mathrm{del} / \mathrm{wt}$ & $\mathrm{M} / \mathrm{M}$ & normal & n.p. \\
\hline
\end{tabular}

$\mathrm{del} / \mathrm{wt}=$ Heterozygous 24-bp deletion in the PRNP gene; del/ $\mathrm{del}=$ homozygous 24-bp deletion in the PRNP gene; none = no cognitive abnormalities; $(+)=$ slight and probably unspecific cognitive abnormalities; $+++=$ severe cognitive abnormalities; $n . p .=$ not performed.

The other relatives of the index patient did not report psychiatric or neurological symptoms, and neurological examination was normal. One sibling (II-4) had normal cognitive function. One sibling (II-1) had minimal impairment of verbal retrieval and verbal error checking. Another sibling (II-5) had slight impairment of figural short-term memory (table 1).

\section{Neuroradiology}

MRI of the index patient showed bilateral, right-dominant parietal lobe atrophy and symmetrical, periventricular confluating $\mathrm{T}_{2}$-hyperintense white matter lesions predominantly located in the parieto-occipital regions (fig. 2a, b). FDG-PET demonstrated decreased FDG uptake of the right hemisphere associated with cerebellar diaschisis (fig. 2e, f). Follow-up cerebral MRI documented slight progression of right hemispheric cortical atrophy whereas the leukoencephalopathy remained unchanged (fig. 2c, d). Repeated cerebral FDG-PET suggested a progressive impairment of the right hemispheric glucose metabolism, and increasing cerebellar diaschisis (fig. 2g, h). The sister (II-3) with PPA had normal cerebral FDG-PET. Brain MRI showed diffuse white matter lesions in both hemispheres, predominantly located in frontal and periventricular regions (data not shown).

\section{Molecular Genetic Analysis}

None of the examined individuals showed mutations in the genomic regions of the MAPT gene with known mutations or in the GRN gene. PRNP sequence analysis 

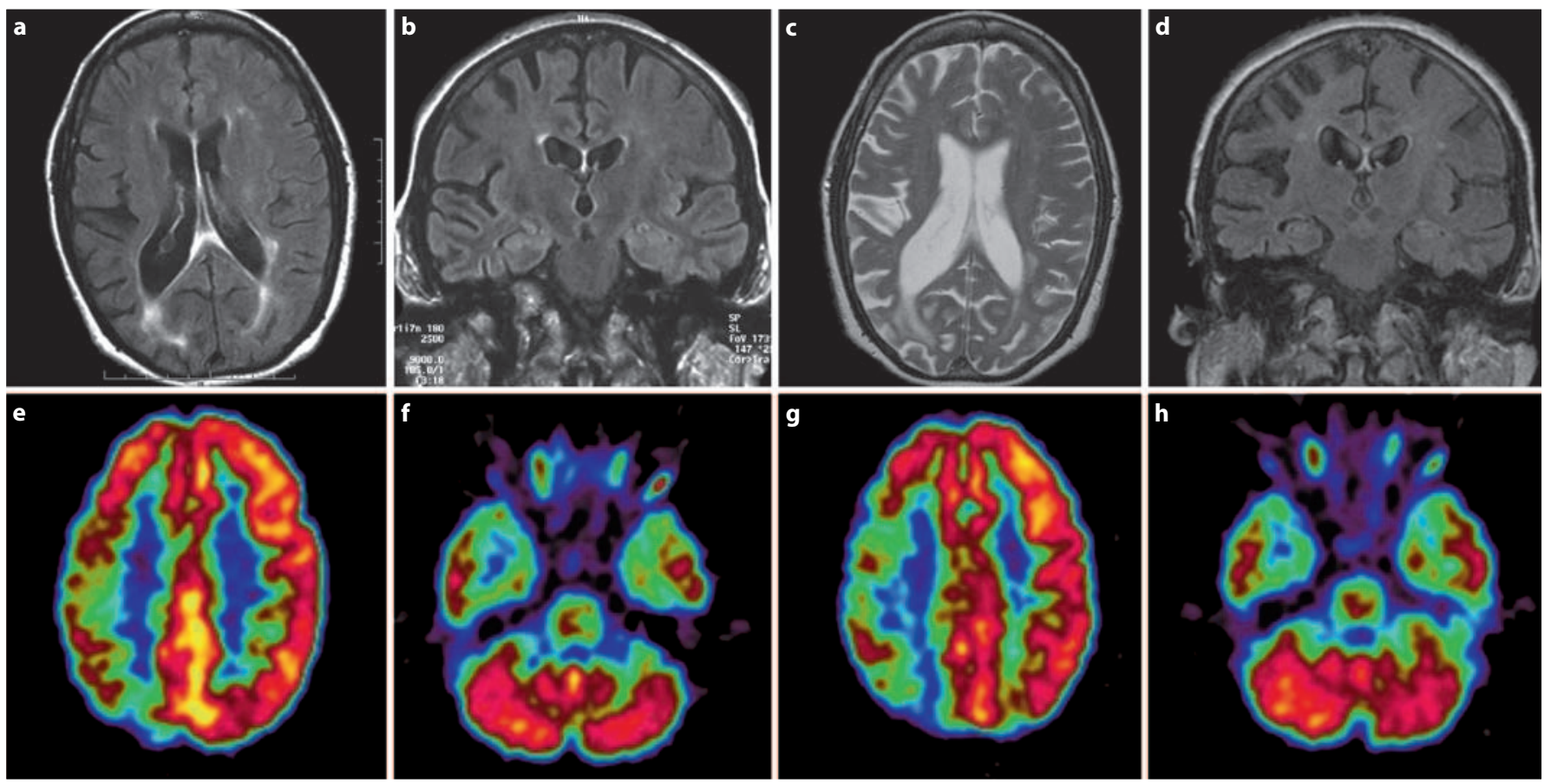

Fig. 2. Imaging. a Flair images show hyperintense symmetrical periventricular confluating white matter lesions predominantly located in the parieto-occipital regions, and less prominently in the frontal white matter and the splenium of the corpus callosum. There were no signal abnormalities in basal ganglia and thalamus. b Flair images demonstrate right-dominant bilateral parietal lobe atrophy. c T2, and d flair repeated cerebral MRI 2 years later doc-

uments a clear progression of hemispheric cortical atrophy, with unchanged posterior leukencephalopathy. e, f FDG-PET demonstrates markedly decreased FDG uptake of the right hemisphere. g, h Repeated cerebral FDG-PET suggest a slightly progressive impairment of the right hemispheric glucose metabolism, and increasing cerebellar diaschisis.

of the index patient (II-2) revealed a homozygous 24-bp deletion in the octapeptide repeat region in the PRNP gene starting at codon 66. Due to the high homology in this region the precise location of the repeat could not be determined. One sibling (II-5) was also homozygous for the 24-bp deletion while all other siblings were heterozygous (table 1). The mother of the index patient was heterozygous. No heterozygous 24-bp deletion in the PRNP gene was found in 200 healthy individuals. Individual II-4 was heterozygous for the Met/Val polymorphism at codon 129 whereas the other siblings were homozygous for the Met allele (table 1).

\section{Neuropathology}

External examination of the index patient's brain revealed slightly asymmetric cortical atrophy which was most pronounced in the right superior frontal and parietal lobes, while the temporal and occipital lobes were almost spared. Coronal sections revealed thinning of the corpus callosum and enlargement of the lateral and third

ventricles. Transverse sections of the brainstem showed pallor of the substantia nigra pars compacta and to a lesser degree of the locus coeruleus.

Histologically, marked neuronal loss, astrocytic gliosis and superficial spongiosis were present in the atrophic cortical regions (fig. 3a). The adjacent subcortical white matter displayed mild to moderate myelin loss and gliosis. In affected cortical areas, mainly in the parietal lobe, scattered ballooned neurons (BN) were noted, immunohistochemically staining for neurofilament, $\alpha \mathrm{B}$-crystallin, and tau antibodies AT8 and RD4 (fig. 3b). Gallyas silver staining, AT8 and RD4 immunohistochemistry revealed numerous astrocytic plaques (fig. 3c). A few astrocytic tau inclusions were reminiscent of tufted astrocytes. Besides BN, cortical neuronal tau pathology was characterized by perinuclear rim-like inclusions, Pick body-like inclusions and some tangle-like inclusions (fig. 3d). Neuronal tau pathology was further noted in basal ganglia, thalamus, substantia nigra and locus caeruleus (fig. 3f). Abundant neuropil threads were noted in affected corti- 

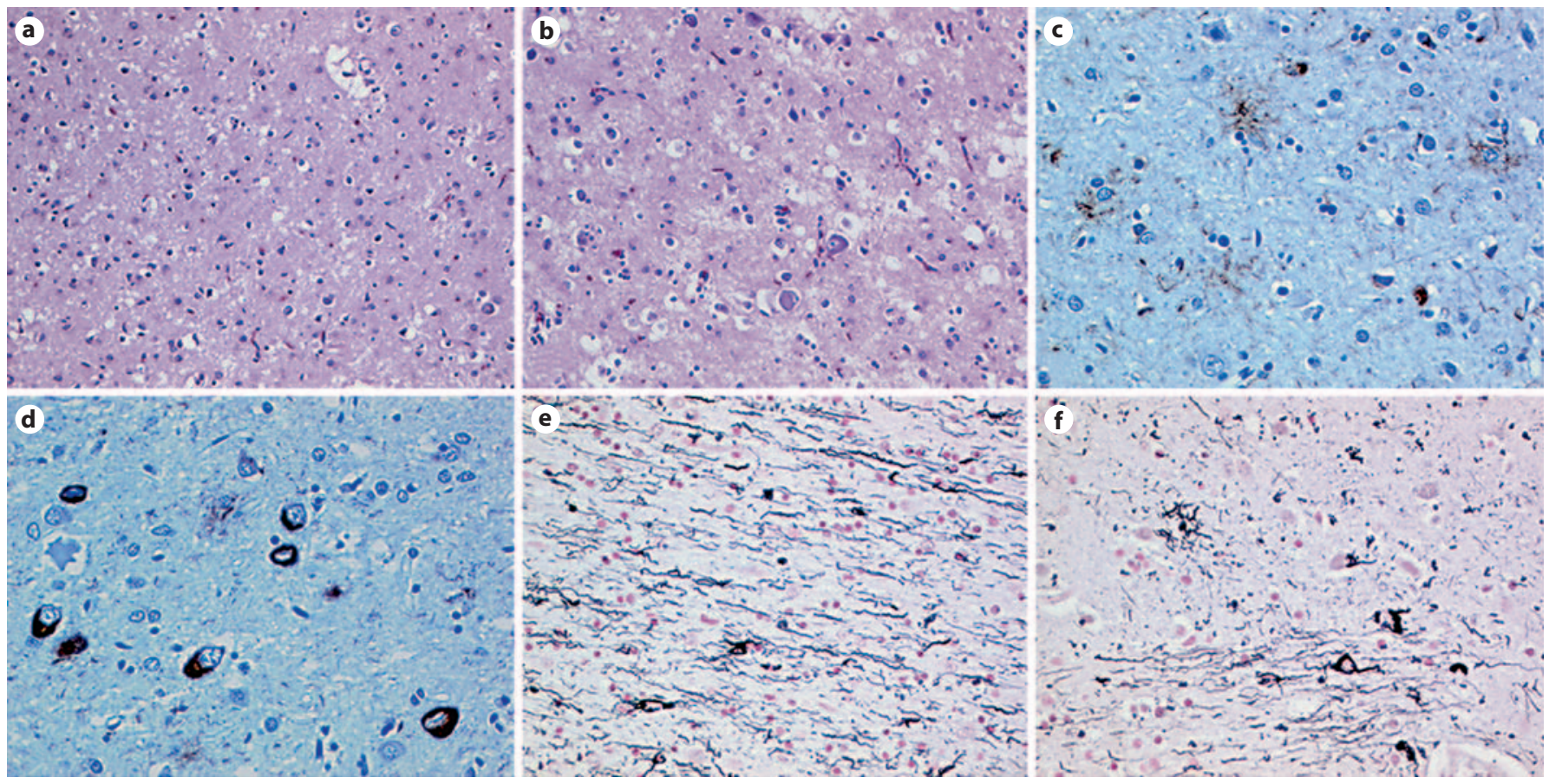

Fig. 3. Brain autopsy findings of the index patient. HE-stained sections of the parietal cortex showing marked neuronal loss, astrogliosis and spongiosis (a) together with some ballooned cells (b). Cortical AT8 stained astrocytic plaques (c) and neuronal tau pathology (d). Gallyas silver stain reveals abundant white matter

neuropil thread-like structures and coiled bodies (e). Gallyas stained thread-like structures in pencil fibers of the striatum in addition to an astrocytic plaque and neuronal tau pathology (f). a $\times 100 ; \mathbf{b} \times 150$; $\mathbf{c} \mathbf{f} \times 200$.

cal and subcortical gray and white matter areas (fig. 3e, f). In white matter areas, there were also numerous coiled bodies. $\beta$-Amyloid plaques, neurofibrillary flame-shaped tangles (except few in sector CA2 of the hippocampus), argyrophilic grains as well as Lewy bodies and Lewy neurites were absent (data not shown). Western blot analysis of brain homogenates revealed no $\operatorname{PrP}^{\mathrm{Sc}}$ (data not shown). Based on these findings, the neuropathological analysis confirmed the clinical diagnosis of CBD.

The diagnosis of CBD was further corroborated by Western blot analysis of sarkosyl-insoluble tau extracted from various regions of the index patient's brain. Antibodies AT8 and AT100 strongly labeled two bands at 68 and $64 \mathrm{kDa}$ (fig. 4b). A slight band at $60 \mathrm{kDa}$ was also observed in the hippocampus of the index patient which is most likely due to the presence of some neurofibrillary tangles found in sector CA2 (see above). By electron microscopy, filaments in the sarkosyl-insoluble tau extracts were labeled with antibody AT8 (fig. 4a). Filaments were predominantly 'narrow twisted ribbons' as reported in other hereditary tauopathies [16]. SDS-PAGE revealed the presence of $3 \mathrm{R}$ and $4 \mathrm{R}$ tau isoforms in similar ratios in- distinguishable from soluble tau extracted from a control brain (fig. 4c). The soluble tau fraction yielded no pattern shift following treatment with lambda-phosphatase, and the bands aligned with all six isoforms of recombinant tau (fig. 4c). In contrast, lambda-phosphatase treatment of sarkosyl-insoluble tau from the temporal cortex of the index patient caused a shift in the band pattern visualized by BR134 and HT7 staining with bands aligning predominantly with $4 \mathrm{R}$ recombinant tau isoforms (fig. $4 \mathrm{~d}$ ).

Records from the index patient's mother reported 'brain atrophy' without further specifications. Histologically, mild neuron loss and astrogliosis were found in the striatum while the hippocampus and cerebellum were normal. In the striatum, Gallyas stain and AT8 immunostaining revealed abundant neuropil thread-like processes in the internal capsule, in the pencil fibers, but also in gray matter of the striatum (fig. 5a, b). In the latter, there was neuronal tau-pathology, sometimes shaped as globose neurofibrillary tangles (fig. 5c). Tufted astrocytes were not noted. Tau-pathology was strongly stained with anti-tau antibodies AT8 and RD4 (fig. 5c), but not with antibody RD3 direct against 3R tau isoforms (fig. 5d). 


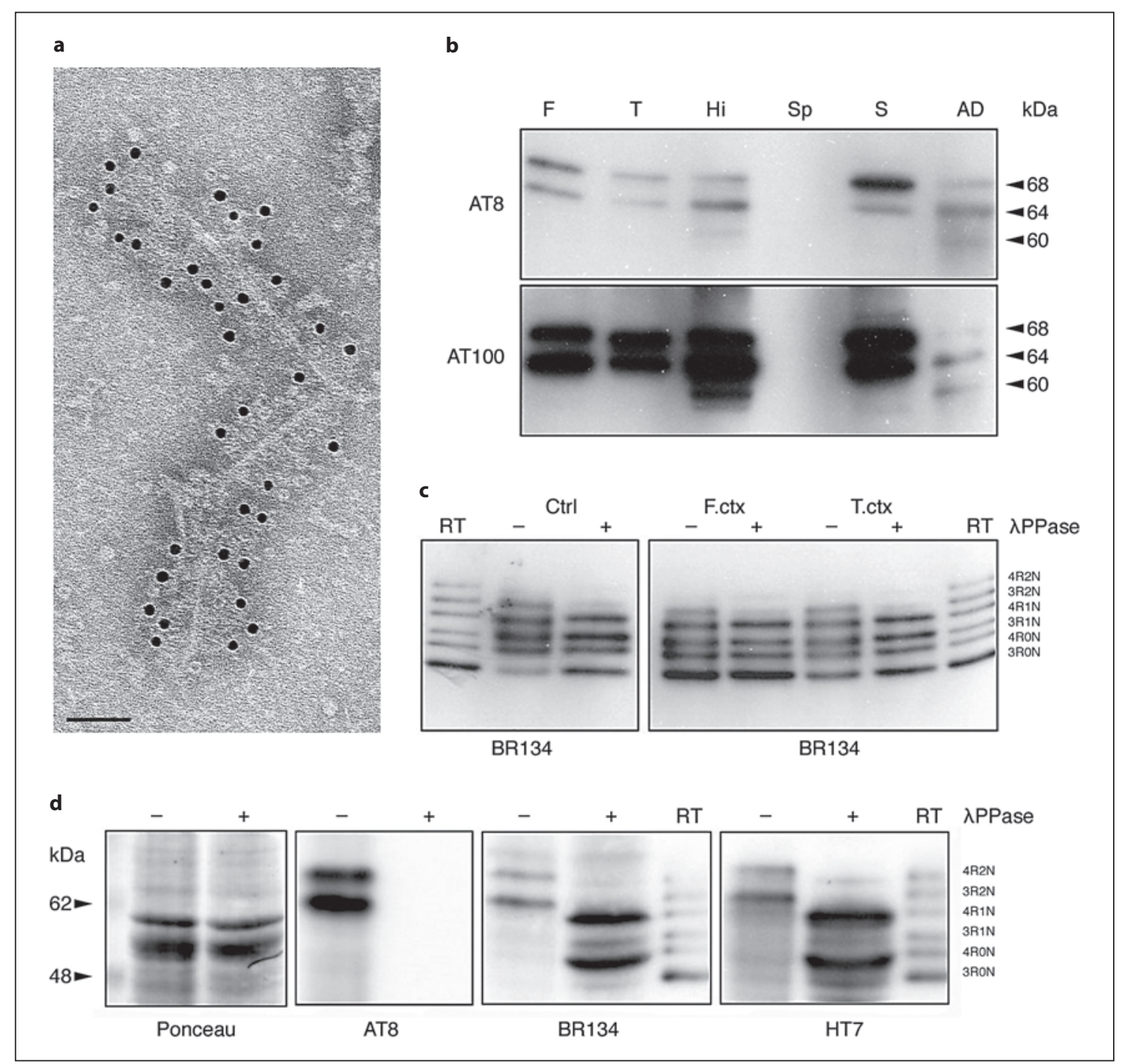

Fig. 4. EM and biochemical analysis of tau pathology of the index patient. a Electron micrograph of tau filaments isolated from the sarkosyl-insoluble tau fraction shows labelling with antibody AT8. Scale bar $=100 \mathrm{~nm}$. b Immunoblot of sarcosyl-insoluble tau stained with antibodies AT8 and AT100 shows two major bands at 68 and $64 \mathrm{kDa}$ in the frontal (F) and temporal (T) cortex, hippocampus (Hi), and striatum (S) but not in the spinal cord $(\mathrm{Sp})$ which was found to be devoid of tau pathology. The slight tau band at $60 \mathrm{kDa}$ in the hippocampus is likely due to the presence of some paired helical filaments. Immunoblot of PHF-tau extracted from the brain of an Alzheimer patient (AD) shows three major bands at 68, 64 and $60 \mathrm{kDa}$. c BR134 staining reveals similar ratios of $3 \mathrm{R}$ and $4 \mathrm{R}$ tau isoforms in the heat stable soluble tau fraction of the index patients frontal (F.ctx) and temporal (T.ctx) cortex when compared to a control (Ctrl) brain. No shift is observed after lambda-phosphatase (+) treatment and the bands align with all isoforms of recombinant tau (RT). d Sarkosyl-insoluble tau dephosphorylated with lambda-phosphatase (+) and immunoblotted with phosphorylation-independent anti-tau antibodies BR134 and HT7. Two major bands align predominantly with recombinant $4 \mathrm{R}$ tau isoforms (4R0N and $4 \mathrm{R} 1 \mathrm{~N})$. Immunoblotting with phosphorylation-dependent anti-tau antibody AT8 confirms efficient dephosphorylation of the sample while Ponceau staining shows similar protein loading.
Abundant tau-pathology was further noted in a small strip of the subcortical insular white matter (fig. 5e). In hippocampal sector CA2, several neurofibrillary tangles (NFT) were visualized by Gallyas and AT8 staining (fig. 5f). There were no NFT in other hippocampal sectors and adjacent parahippocampal cortex. Selective neurofibrillary degeneration of hippocampal sector CA2 has recently been described in $4 \mathrm{R}$ tauopathies [17]. $\beta$-Amyloid plaques, $\mathrm{PrP}^{\mathrm{Sc}}$ deposits (3F4 immunohistochemistry) and Lewy pathology were absent (data not shown). 

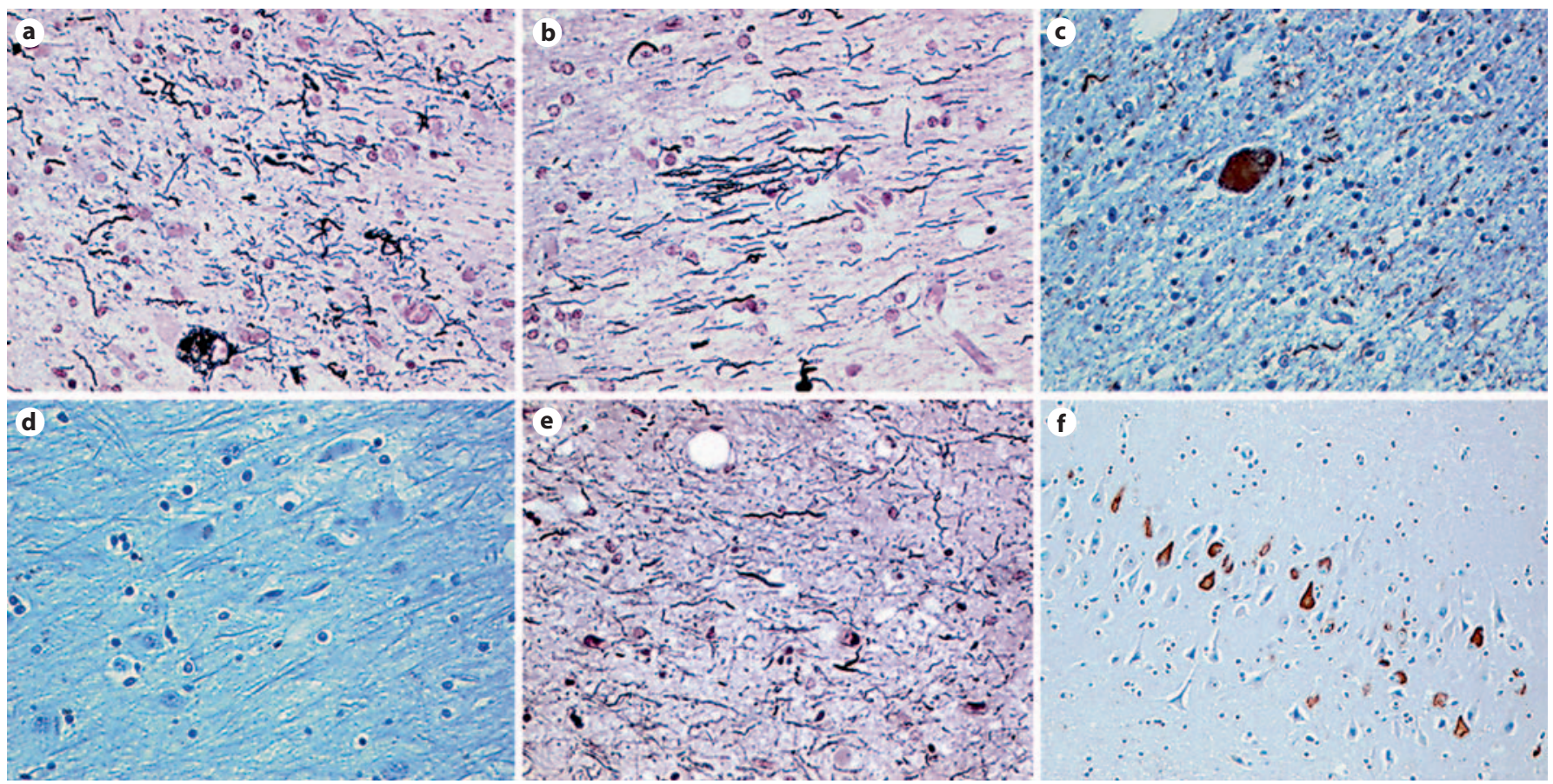

Fig. 5. Histopathological findings of the index patient's mother. Gallyas stain of the striatum shows abundant thread-like structures, neuronal tau pathology and coiled bodies in the gray matter (a) as well as in the pencil fibers (b). Thread-like structures and a globose tangle stained with anti-tau antibody RD4 recognizing
$4 \mathrm{R}$ tau isoforms (c). Tau pathology is not detected by anti-tau antibody RD3 directed against 3R tau isoforms (d). Abundant white matter tau-pathology obtained with Gallyas silver stain (e). AT8 stained neurofibrillary tangles in sector CA2 of the hippocampus (f). a-e $\times 200 ; \mathbf{f} \times 100$.
Although there were limitations in the pathological investigation of the index patient's mother, histological and immunohistochemical features were strongly suggestive for CBD.

\section{Discussion}

The index patient fulfilled the proposed clinical criteria for CBD including asymmetrical rigidity and dystonia nonresponsive to L-dopa with insidious onset and progressive course, signs of cortical dysfunction including apraxia and hemineglect $[3,18]$. The neuroradiological findings were in line with this diagnosis, demonstrating progressive asymmetrical cortical atrophy with frontoparietal predominance supported [19]. In the index patient's mother, diagnosis of Parkinson's disease was made. History of progressive gait problems, frequent falls, and bradykinesia suggested a PSP-like phenotype. The histopathological findings, however, confirmed the diagnosis of $\mathrm{CBD}$, thus being compatible with autosomal-dominant inheritance [20]. In both patients, there were no early language deficits such as paraphasias or word-finding difficulties. By contrast, the sister of the index patient (II-3) suffers from PPA without evidence for a movement disorder.

The family pedigree suggests autosomal-dominant inheritance of a neurodegenerative disease presenting as CBD, Parkinsonism (possibly PSP) and PPA. Since no pathological examination is available in the index case's sister with PPA, a different pathologic phenotype such as tau- or TDP-43-positive frontotemporal dementia (FTD) cannot formally be excluded. In the affected family members, we were unable to detect a causative mutation in $M A P T$. Similarly, in other families with hereditary PSP/ $\mathrm{CBD}$, mutational screening of the MAPT gene revealed no evidence for a pathogenic mutation [11]. Pathogenic MAPT mutations were only found in a subset of families with hereditary PSP despite extensive analysis of the $M A P T$ gene [21-24]. Although we cannot exclude that a MAPT mutation could have been missed by our mutational screening, causative mutations in other genes upor downstream the tau metabolic pathway might be present. Although mutations in GRN are mainly linked to FTLD with TDP-43 pathology, they can also be associ- 
ated with $\mathrm{CBD}$ and tau-positive cytoplasmatic neuronal inclusions in rare cases [25]. Therefore, we excluded mutations in GRN in our index patient. Genetic linkage of familial PSP to an alternative locus on chromosome 1 has recently been demonstrated [24]. Since there were only two informative meioses available in our family, testing for linkage to this locus was not feasible.

The diverse clinicopathological phenotypes of hereditary $4 \mathrm{R}$ tauopathies might represent different points on a single disease spectrum and additional genetic or epigenetic factors might contribute to the phenotypic diversity [1, 26-28]. Variable clinical manifestations in families with hereditary tauopathy with MAPT mutation P301S as either PSP or CBD have previously been described [29, 30]. CBD is also known to overlap PPA and FTD. Wordfinding difficulties and other cognitive deficits are frequent presenting symptoms in CBD $[27,31]$. One study investigated patients who presented with PPA or FTD and developed movement disorder/ symptoms of CBD over time. In these patients, the average time between primary manifestation as PPA or FTD and diagnosis of CBD was 2.5 years, including patients who developed CBD 7 years later [32]. Therefore, we cannot exclude that our patient II-3 will develop symptoms of CBD over time.

The high amount of protein 14-3-3 in the CSF of our index patient prompted us to consider $P R N P$ as a candi- date disease-modifying gene. $P R N P$ sequence analysis revealed a homozygous 24 -bp deletion in the octapeptide repeat region of the PRNP gene. Disease-causing PRNP mutations are coding point mutations or integral numbers of octapeptide repeats insertions [33]. The role of deletions in PRNP is less clear [33]. Population-based examinations estimated a prevalence of the heterozygous 24-bp deletion of up to $0.5 \%$, which was therefore as a benign polymorphism not predisposing individuals to prion diseases [34].

Nevertheless, it is likely that other yet unidentified genetic modifiers and/or environmental factors are involved in phenotypic variation in our family with hereditary tauopathy.

\section{Acknowledgements}

We gratefully thank all family members who participated in this study. We thank S.S. Kollias and A. Buck for the supervision of MRI and PET examinations, F. Baumann for helpful discussions, and Marleen Van den Broeck for the genetic testing. We also thank R. Maurer for generously providing the autopsy material. We are indebted to M. Wacker and M. Fritsi for excellent laboratory work. M.G. Spillantini and K. Virdee were generously supported by the EU Integrated project APOPIS and the Medical Research Council. M. Tolnay is supported by the Swiss National Science Foundation (3100-068328).

\section{References}

1 Lee VM, Goedert M, Trojanowski JQ: Neurodegenerative tauopathies. Annu Rev Neurosci 2001;24:1121-1159.

2 McKhann GM, Albert MS, Grossman M, Miller B, Dickson D, Trojanowski JQ: Clinical and pathological diagnosis of frontotemporal dementia: report of the work group on frontotemporal dementia and pick's disease. Arch Neurol 2001;58:1803-1809.

-3 Litvan I, Bhatia KP, Burn DJ, Goetz CG, Lang AE, McKeith I, Quinn N, Sethi KD, Shults C, Wenning GK: Movement disorders society scientific issues committee report: Sic task force appraisal of clinical diagnostic criteria for parkinsonian disorders. Mov Disord 2003; 18:467-486

4 Feany MB, Mattiace LA, Dickson DW: Neuropathologic overlap of progressive supranuclear palsy, Pick's disease and corticobasal degeneration. J Neuropathol Exp Neurol 1996;55:53-67.

5 Litvan I, Grimes DA, Lang AE, Jankovic J, McKee A, Verny M, Jellinger K, Chaudhuri KR, Pearce RK: Clinical features differentiating patients with postmortem confirmed progressive supranuclear palsy and cortico- basal degeneration. J Neurol 1999;246(supp 2):II1-II5.

6 Josephs KA, Petersen RC, Knopman DS, Boeve BF, Whitwell JL, Duffy JR, Parisi JE, Dickson DW: Clinicopathologic analysis of frontotemporal and corticobasal degenerations and PSP. Neurology 2006;66:41-48.

7 Mackenzie IR, Neumann M, Bigio EH, Cairns NJ, Alafuzoff I, Kril J, Kovacs GG, Ghetti B, Halliday G, Holm IE, Ince PG, Kamphorst W, Revesz T, Rozemuller AJ, Kumar-Singh S, Akiyama H, Baborie A, Spina S, Dickson DW, Trojanowski JQ, Mann DM: Nomenclature and nosology for neuropathologic subtypes of frontotemporal lobar degeneration: an update. Acta Neuropathol 2010;119:1-4.

8 Goedert M, Spillantini MG, Jakes R, Rutherford D, Crowther RA: Multiple isoforms of human microtubule-associated protein tau: sequences and localization in neurofibrillary tangles of Alzheimer's disease. Neuron 1989;3:519-526.

-9 Tolnay M, Clavaguera F: Argyrophilic grain disease: a late-onset dementia with distinctive features among tauopathies. Neuropathology 2004;24:269-283.
10 Goedert M, Jakes R: Mutations causing neurodegenerative tauopathies. Biochim Biophys Acta 2005;1739:240-250.

11 Tuite PJ, Clark HB, Bergeron C, Bower M, St George-Hyslop P, Mateva V, Anderson J, Knopman DS: Clinical and pathologic evidence of corticobasal degeneration and progressive supranuclear palsy in familial tauopathy. Arch Neurol 2005;62:14531457.

12 Baker M, Litvan I, Houlden H, Adamson J, Dickson D, Perez-Tur J, Hardy J, Lynch T, Bigio $\mathrm{E}$, Hutton $\mathrm{M}$ : Association of an extended haplotype in the tau gene with progressive supranuclear palsy. Hum Mol Genet 1999;8: 711-715.

13 Houlden H, Baker M, Morris HR, MacDonald N, Pickering-Brown S, Adamson J, Lees AJ, Rossor MN, Quinn NP, Kertesz A, Khan MN, Hardy J, Lantos PL, St George-Hyslop P, Munoz DG, Mann D, Lang AE, Bergeron C, Bigio EH, Litvan I, Bhatia KP, Dickson D, Wood NW, Hutton M: Corticobasal degeneration and progressive supranuclear palsy share a common tau haplotype. Neurology 2001;56:1702-1706. 
-14 Cruts M, Gijselinck I, van der Zee J, Engelborghs S, Wils H, Pirici D, Rademakers R, Vandenberghe R, Dermaut B, Martin JJ, van Duijn C, Peeters K, Sciot R, Santens P, De Pooter T, Mattheijssens M, Van den Broeck M, Cuijt I, Vennekens K, De Deyn PP, Kumar-Singh S, Van Broeckhoven C: Null mutations in progranulin cause ubiquitin-positive frontotemporal dementia linked to chromosome 17q21. Nature 2006;442:920924.

- 15 Goedert M, Spillantini MG, Cairns NJ, Crowther RA: Tau proteins of alzheimer paired helical filaments: abnormal phosphorylation of all six brain isoforms. Neuron 1992;8:159-168.

-16 Spillantini MG, Crowther RA, Kamphorst W, Heutink P, van Swieten JC: Tau pathology in two Dutch families with mutations in the microtubule-binding region of tau. Am J Pathol 1998:153:1359-1363.

-17 Ishizawa T, Ko LW, Cookson N, Davias P, Espinoza M, Dickson DW: Selective neurofibrillary degeneration of the hippocampal ca2 sector is associated with four-repeat tauopathies. J Neuropathol Exp Neurol 2002; 61:1040-1047.

18 Boeve BF, Lang AE, Litvan I: Corticobasal degeneration and its relationship to progressive supranuclear palsy and frontotemporal dementia. Ann Neurol 2003;54(suppl 5):S15S19.

19 Hauser RA, Murtaugh FR, Akhter K, Gold $\mathrm{M}$, Olanow CW: Magnetic resonance imaging of corticobasal degeneration. J Neuroimaging 1996;6:222-226.

20 Dickson DW, Bergeron C, Chin SS, Duyckaerts C, Horoupian D, Ikeda K, Jellinger K, Lantos PL, Lippa CF, Mirra SS, Tabaton M, Vonsattel JP, Wakabayashi K, Litvan I: Office of rare diseases neuropathologic criteria for corticobasal degeneration. J Neuropathol Exp Neurol 2002;61:935-946.
21 Stanford PM, Halliday GM, Brooks WS, Kwok JB, Storey CE, Creasey H, Morris JG, Fulham MJ, Schofield PR: Progressive supranuclear palsy pathology caused by a novel silent mutation in exon 10 of the tau gene: expansion of the disease phenotype caused by tau gene mutations. Brain 2000;123:880893.

22 Morris HR, Katzenschlager R, Janssen JC, Brown JM, Ozansoy M, Quinn N, Revesz T, Rossor MN, Daniel SE, Wood NW, Lees AJ Sequence analysis of tau in familial and sporadic progressive supranuclear palsy. J Neurol Neurosurg Psychiatry 2002;72:388-390.

23 Ros R, Thobois S, Streichenberger N, Kopp N, Sanchez MP, Perez M, Hoenicka J, Avila J, Honnorat J, de Yebenes JG: A new mutation of the tau gene, g303v, in early-onset familial progressive supranuclear palsy. Arch Neurol 2005;62:1444-1450.

24 Ros R, Gomez Garre P, Hirano M, Tai YF, Ampuero I, Vidal L, Rojo A, Fontan A, Vazquez A, Fanjul S, Hernandez J, Cantarero S, Hoenicka J, Jones A, Ahsan RL, Pavese N, Piccini P, Brooks DJ, Perez-Tur J, Nyggard T, de Yebenes JG: Genetic linkage of autosomal dominant progressive supranuclear palsy to 1q31.1. Ann Neurol 2005;57:634-641.

25 Yu CE, Bird TD, Bekris LM, Montine TJ, Leverenz JB, Steinbart E, Galloway NM, Feldman H, Woltjer R, Miller CA, Wood EM, Grossman M, McCluskey L, Clark CM, Neumann M, Danek A, Galasko DR, Arnold SE, Chen-Plotkin A, Karydas A, Miller BL, Trojanowski JQ, Lee VM, Schellenberg GD, Van Deerlin VM: The spectrum of mutations in progranulin: a collaborative study screening 545 cases of neurodegeneration. Arch Neurol 2010;67:161-170.
26 Scaravilli T, Tolosa E, Ferrer I: Progressive supranuclear palsy and corticobasal degeneration: Lumping versus splitting. Mov Disord 2005;20(suppl 12):S21-S28.

27 Sha S, Hou C, Viskontas IV, Miller BL: Are frontotemporal lobar degeneration, progressive supranuclear palsy and corticobasal degeneration distinct diseases? Nat Clin Pract Neurol 2006;2:658-665.

28 Williams DR, Lees AJ: Progressive supranuclear palsy: Clinicopathological concepts and diagnostic challenges. Lancet Neurol 2009;8:270-279.

29 Bugiani O, Murrell JR, Giaccone G, Hasegawa M, Ghigo G, Tabaton M, Morbin M, Primavera A, Carella F, Solaro C, Grisoli M, Savoiardo M, Spillantini MG, Tagliavini F, Goedert M, Ghetti B: Frontotemporal dementia and corticobasal degeneration in a family with a p301s mutation in tau. J Neuropathol Exp Neurol 1999;58:667-677.

-30 Casseron W, Azulay JP, Guedj E, Gastaut JL, Pouget J: Familial autosomal dominant cortico-basal degeneration with the p301s mutation in the tau gene: an example of phenotype variability. J Neurol 2005;252:1546-1548.

31 Grimes DA, Lang AE, Bergeron CB: Dementia as the most common presentation of cortical-basal ganglionic degeneration. Neurology 1999;53:1969-1974.

-32 Kertesz A, Martinez-Lage P, Davidson W, Munoz DG: The corticobasal degeneration syndrome overlaps progressive aphasia and frontotemporal dementia. Neurology 2000; 55:1368-1375.

>33 Kovacs GG, Trabattoni G, Hainfellner JA, Ironside JW, Knight RS, Budka H: Mutations of the prion protein gene phenotypic spectrum. J Neurol 2002;249:1567-1582.

>34 Palmer MS, Mahal SP, Campbell TA, Hill AF, Sidle KC, Laplanche JL, Collinge J: Deletions in the prion protein gene are not associated with cjd. Hum Mol Genet 1993;2:541544 